\title{
ANALISIS PENGARUH KECEPATAN LINGKAR DAN WAKTU TARIK TERHADAP HASIL TANGKAPAN PUKAT CINCIN
}

\section{Analysis of the Effect of Circular Speed and Tow Time on the Catching of Purse Seine}

\author{
Kadi Istrianto $^{1}$, Suharyanto ${ }^{1}$, Deni Sarianto ${ }^{2 *}$, Aidil Fitra ${ }^{2}$ \\ ${ }^{1}$ Program Studi Perikanan Tangkap Politeknik Kelautan dan Perikanan Karawang \\ ${ }^{2}$ Program Studi Perikanan Tangkap Politeknik Kelautan dan Perikanan Pariaman \\ *corresponding author: denisarianto45@gmail.com
}

\begin{abstract}
ABSTRAK
Pelabuhan Perikanan Nusantara (PPN) Prigi merupakan salah satu pelabuhan Tipe B yang terdapat di Provinsi Jawa Timur yang berhadapan langsung dengan Samudera Hindia bagian timur. Salah satu alat tangkap yang digunakan adalah pukat cincin. Tujuan penelitian ini adalah untuk menganalisis pengaruh kecepatan kapal saat setting dan lama waktu penarikan tali kerut terhadap hasil tangkapan. Penelitian ini dilakukan pada musim peralihan barat yaitu bulan Maret - Mei 2020 di pantai selatan laut Jawa. Hasil dari koefisien korelasi untuk waktu lingkar dan hasil tangkapan, waktu tarik dan hasil tangkapan masing-masing adalah sebesar 0,589 dan 0,428 yang berarti hubungan antara waktu lingkar, waktu tarik dan hasil tangkapan sama-sama cukup kuat. Berdasarkan analisis regresi linier sederhana waktu lingkar dan waktu tarik masing - masing memiliki pengaruh yang signifikan terhadap total hasil tangkapan dengan koefisien regresi bernilai negative yang berarti setiap peningkatan waktu tarik dan waktu lingkar maka akan menurunkan hasil tangkapan. Jenis ikan pelagis yang dominan tertangkap adalah layang deles, tongkol lisong, tembang, cakalang, layang benggol, peperek, layang angur, tongkol komo.
\end{abstract}

Kata kunci: Hasil tangkapan, waktu lingkar, waktu tarik

\begin{abstract}
Prigi Archipelago Fishery Port (PPN) is one of the type B ports located in East Java Province which is directly opposite the Eastern Indian Ocean. One of the fishing gear used is a purse seine. The purpose of this study was to analyze the effect of the speed of the ship when setting and the length of time for pulling the corrugated rope on the catch. This research was conducted in the western transition season, namely March - May 2020 on the southern coast of the Java Sea. The results of the correlation coefficients for loop time and catch, towing time and catch are 0.589 and 0.428 , respectively, which means that the relationship between loop time, towing time and catch is quite strong. Based on simple linear regression analysis, the loop time and towing time each have a significant effect on the total catch with a negative regression coefficient, which means that every increase in towing time and loop time will decrease the catch. The dominant types of pelagic fish caught were deles kites, lisong tuna, tembang, skipjack tuna, benggol kites, peperek, angur kites, komo tuna.
\end{abstract}

Keyword: Catches, Loop time, tow time 


\section{PENDAHULUAN}

Pelabuhan Perikanan Nusantara (PPN) Prigi merupakan salah satu pelabuhan Tipe $B$ yang terdapat di Provinsi Jawa Timur. PPN ini berhadapan langsung dengan Samudera Hindia bagian timur atau berada di wilayah pengelolahan perikanan Republik Indonesia 573 (WPPRI). PPN Prigi memiliki 978 unit armada dengan 5 jenis alat tangkap utama yaitu: pukat cincin, pancing tonda, pancing ulur, payang, jaring insang. Pancing ulur merupakan alat tangkap utama dengan $70 \%$ armada atau 694 unit armada. Selanjutnya di ikuti oleh pukat cincin sebesar $16 \%$ atau 160 unit armada. (KKP 2018).

Dengan 160 unit armada pukat cincin mampu menguasat $93,93 \%$ total produksi perikanan PPN Prigi atau 26.744.587 kg. (KKP 2018). Melihat tingginya produksi pukat cincin akan memberi pengaruh yang besar terhadap sumberdaya ikan di perairan. (Olii dan Iwan, 2018) menyatakan prinsip kerja alat tangkap akan berpengaruh terhadap hasil tangkapan. Pukat cincin merupakan jaring lingkar berbentuk empat persegi panjang yang dilengkapi cincin dan tali kerut, pengoperasiannya mengkerutkan jaring pada bagian bawah dengan cara menarik tali kerut yang pengoperasiannya menggunakan satu kapal atau dua kapal. Karakteristik purse seine terletak pada cincin dan kantonya (Martasuganda et al., 2004)

Pukat cincin memiliki prinsip pengoperasian melingkari gerombolan ikan dengan jaring, kemudian jaring kemudian menarik tali cincin dengan cepat agar bagian bawah tertutup seperti kerucut untuk memperkecil ruang gerak ikan. Keberhasilan penangkapan pada pukat cincin di pengaruhi oleh faktor internal dan eksternal. Faktor internal yang data dari kapal berupa panjang kapal, panjang pukat cincin serta kekuatan mesin induk kapal. Sedangkan faktor eksternal berasal dari luar kapal berupa gelombang dan arus.

Kecepatan kapal merupakan hasil dari faktor internal dan eksternal dimana sangat menentukan keberhasilan penangkapan dengan pukat cincin. Makin cepat kapal dalam melingkari gerombolan ikan maka makin kecil peluang ikan dapat meloloskan diri. Namun setelah melingkari gerombolan ikan kecepatan penarikan tali kerut juga menjadi penentu seberapa banyak ikan yang terperangkap dalam jaring. Kecepatan lingkar dan kecepatan penarikan tali kerut menjadi penentu apakah armada tangkap tersebut memperoleh keuntungan. Oleh karna itu, penelitian ini bertujuan untuk mengetahui pengaruh kecepatan kapal saat setting dan lama waktu penarikan tali kerut terhadap hasil tangkapan.

\section{BAHAN DAN METODE Metode penelitian}

Penelitian dilakukan pada musim peralihan barat yaitu bulan Maret - Mei 2020. Di perairan samudera hindia bagian timur atau pantai selatan Pulau Jawa. Penelitian menggunakan Kapal Motor (KM) Sinar Mutiara. Daerah penangkapan ikan tersebar dari $8^{\circ} 57^{\prime} \mathrm{LS}$ sampai $9^{\circ} 25^{\prime} \mathrm{LS}$ dan $111^{\circ} 53^{\prime} \mathrm{BT}$ sampai $112^{\circ} 22^{\prime}$ BT. Gambar 1. merupakan peta daerah penangkapan. 


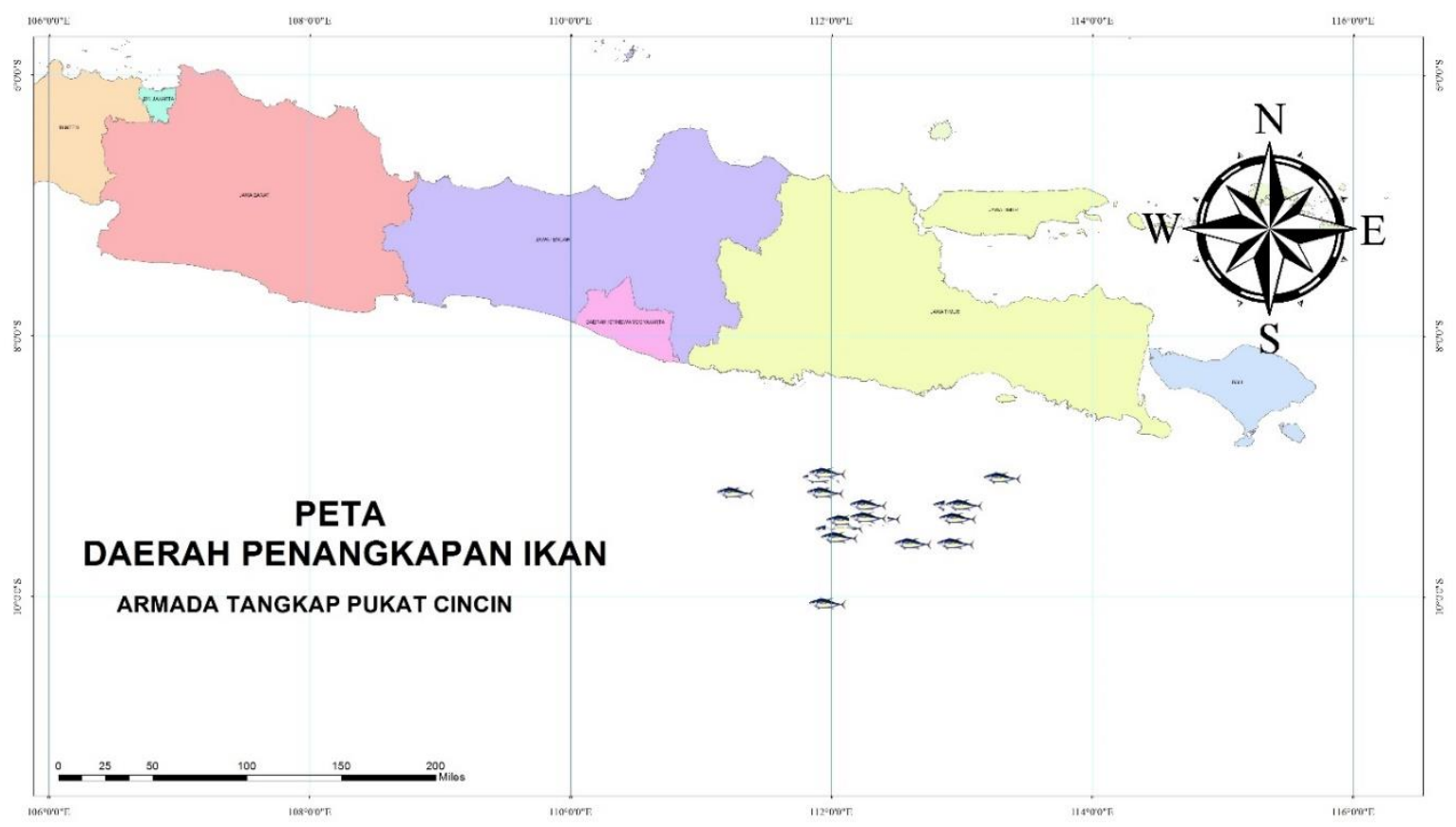

Gambar 1. Peta Sebaran Daerah Penangkapan Ikan

Metode yang digunakan dalam penelitian ini adalah metode observasi. Observasi adalah penyelidikan yang dilakukan untuk memperoleh fakta dan gejala-gejala yang ada dilapangan (Arikunto, 2019). Daerah penangkapan di hitung berdasarkan posisi yang terdapat pada fish finder saat melakukan aktifitas penangkapan. Data koordinat penangkapan diolah dengan mengunakan sofwer ArcGis 10.2 dan disajakan dalam bentuk gambar.

\section{Alat dan Bahan}

Alat tangkap yang digunakan merupakan alat tangkap pukat cincin berbentuk empat persegi memiliki panjang 500 meter, lebar 40,5 meter, ukuran mata linci, 2 inci, dan 4 inci. Ukuran dari tiap-tiap mata jaring secara berurutan terdiri dari 3 inci dengan panjang 500 meter, 2 inci dengan panjang 200 meter, 1,5 inci dengan panjang 100 meter serta 1 inci ukuran mata jaring 100 meter pada bagian kantong terlihat pada gambar 2.

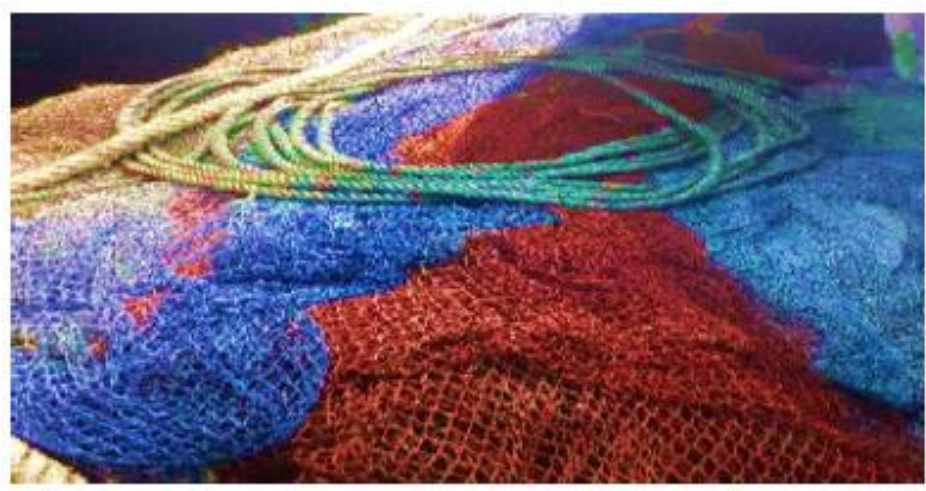

Gambar 2. Alat Tangkap Pukat Cincin

\section{Prosedur Pengoperasian}

Setting

Proses penurunanan alat tangkap atau setting dimulai dengan menurunkan pelampung tanda serta diikuti oleh menurunkan cincin-cincin, pemberat dan bada jaring sambil melingkari gerombolan ikan. Setelah membentuk lingkaran maka 
setting sudah berakahir dan selanjutnya memasuki proses hauling. Kegiatan setting dilakukan berlawan dengan arah arus agar alat jaring dapat terbuka secara sempurna serta bagian jaring tidak menyangkut pada baling-baling kapal. (Pravin, 2002) menyatakan kekuatan arus perairan dan kontur perairan menentukan keberhasilan pengoperasian pukat cincin.

\section{Hauling}

Setelah proses setting selesai di ikuti dengan penarikan pelampung tanda keatas kapal. Sekaligus penarikan tali kerut. Kegiatan ini bertujuan agar jaring berbentuk kantong sehingga ikan tidak bisa lolos. Tali kerut di Tarik menggunakan garden yang terhubung kemesin induk. Penarikan dilakukan dengan cepat untuk mengindari ikan mencari celah pelolosan. Ketika kantong sudah terbentuk dan cincin-cincin sudah di atas kapal selanjutnya dilakukan penarikan pemberat, badan jaring serta pelampung sampai tingggal sebagian kecil badan jaring serta pelampung. pada saat ini akan dilakukan pegambilan ikan dalam jaring mengunakan serok. (Pravin, 2002) menyatakan proses hauling memakan waktu \pm 1 jam.

\section{Teknik Analisis Data}

Analisis data yang digunakan untuk melihat hubungan kecepatan lingkar dan kecepatan tarik tali cincin menggunakan regresi linear sederhana. Analisis Regresi adalah persamaan matematika yang memungkinkan kita meramalkan nilai-nilai variabel tak bebas (y) dengan satu atau lebih variabel bebas (x) Suryana et al, 2013 dalam (Yanis et al., 2018) adalah sebagai berikut:

Keterangan:

$$
y=a+b x
$$

$\mathrm{y}=$ Hasil Tangkapan $(\mathrm{kg})$

$\mathrm{a}=$ Parameter intercept

$b=$ Parameter koefisien regresi variabel

bebas

$\mathrm{x}=$ Lama waktu pelingkar (detik)
Data diolah mengunakan aplikasi SPSS 26 untuk mendapatkan nilai keeratan hubungan dan nilai koefisien regresi.

\section{HASIL DAN PEMBAHASAN Kapal Pukat Cincin}

Kapal pukat cincin yang digunakan berbodi kayu dengan lambung berbentuk $\mathrm{V}$ dengan tujuan agar kapal dapat melaju dengan cepat serta mudah melakukan olah gerak. Penelitian ini dilakukan pada kapal motor (KM) Sinar Mutiara dengan tanda selar GT.30 No. 1429/Fp kekuatan mesin 190 PK. Berukuran panjang 14,36 m, lebar 6,08 m, dalamnya $1,57 \mathrm{~m}$, dengan bobot $30 \mathrm{GT}$. Aktivitas penangkapan ikan dilakukan pada malam hari baik pada rumpon ataupun tidak.

\section{Daerah Penangkapan}

Banyaknya aktifitas penangkapan di daerah penangkapan di pengaruhi oleh pergerakan masa air dari laut jawa menuju selat bali atau pun dari Samudera Hindia menuju laut jawa. Dengan bertemunya dua masa air yang berbeda akan meningkatkan kandungan oksigen dalam air serta meningkatnya nutrient. Hal ini senada dengan yang dikatakan oleh (Demi et al., 2020) dan (Simbolon et al., 2013) menyatakan samudera hindia bagian barat dan timur terdapat upwelling. (Nuzapril et al., 2017) menyatakan produktivitas primer perairan sangat mendukung sebaran pada suatu perairan.

\section{Hasil Tangkapan}

Jenis hasil tangkapan yang di daratkan oleh pukat cincin di PPN Prigi berdasarkan jenis ikan pelagis yang dominan tertangkap adalah layang deles, tongkol lisong, tembang, cakalang, layang benggol, peperek, layang angur, tongkol komo. Hasil tangkapan akan berubah mengikuti musim penangkapan dimana setiap terjadi perubahan musim akan terjadi perubahan ikan yang dominan tertangkap. Perubahan jenis ikan yang 
tertangkap dipengaruhi oleh ruaya ikan, kandungan klorofil-a dan suhu permukanaan laut hal ini senada dengan
(Chodrijah dan Hariati, 2017); (Cahya et al., 2016); dan (Tambun et al., 2018).

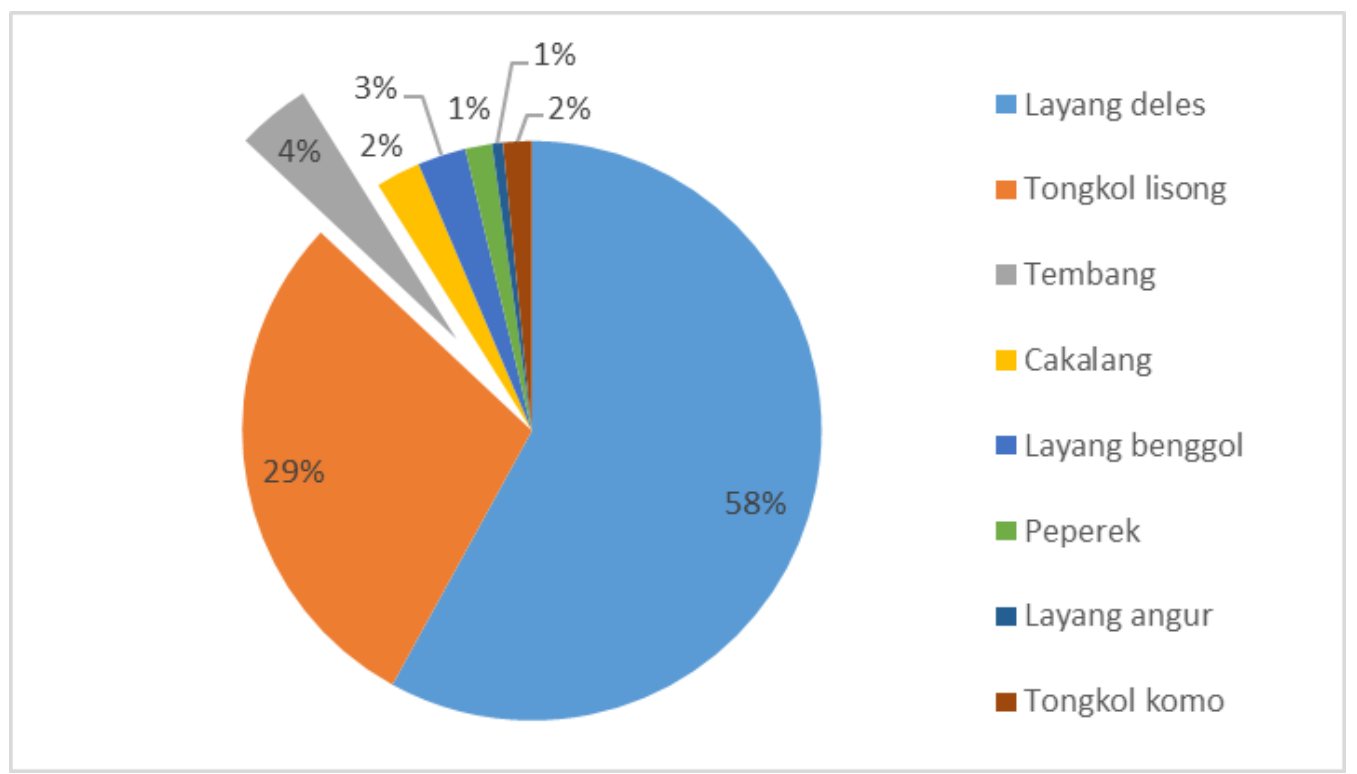

Gambar 1. Jenis hasil Tangkapan

\section{Pengaruh Waktu Lingkar Terhadap Terhadap Hasil Tangkapan}

Waktu pelingkaran jaring yang dibutuhkan dalam satu kali setting berkisar antara 120 - 240 detik dengan rata-rata hasil tangkapan $946 \mathrm{Kg}$. Hasil tangkapan tertinggi diperoleh pada saat pelingkaran dengan waktu 120 detik dengan hasil tangkapan sebanyak 1600 Kg. Tangkapan paling sedikit terjadi pada saat pelingkaran jaring dengan waktu 181 detik. Berdasarkan penelitian (Hermawan et al., 2016) menyatakan kecepatan lingkar tercepat 153 detik mendapatkan hasil tangkapan $591 \mathrm{Kg}$, (Yanis et al., 2018) mencatat kecepatan lingkar tercepat 180 detik dengan hasil tangkapan 1500 $\mathrm{kg}$.

Hasil analisis data yang telah dilakukan dengan menggunakan regresi liner sederhana mendapat nilai koefisien korelasi sebesar 0,589 sehingga dapat diambil kesimpulan bahwa tingkat korelasi atau hubungan linear antar waktu lingkar dengan hasil tangkapan termasuk kedalam kategori cukup kuat. Nilai koefisien determinasi $\mathrm{R}$ Square yang diperoleh sebesar 0,347, dari nilai $\mathrm{R}$ square yang diperoleh dapat disimpulkan bahwa pengaruh waktu lingkar terhadap hasil tangkapan sebesar 0,347 atau 34,7\% dan sisanya $65,3 \%$ dipengaruhi oleh variable lain. Adjusted R Square 0,325 dalam penelitian ini nilai Adjusted $\mathrm{R}$ square tidak digunakan karena variable bebas yang digunakan hanya satu variable, dari data yang telah dipaparkan diatas dapat dilihat pada tabel 1 di bawah ini.

Tabel 1. Ringkasan Statistik Pengaruh Waktu Lingkar Terhadap Hasil Tangkapan

\begin{tabular}{lr}
\hline & Regression Statistics \\
\hline Multiple R & 0,589 \\
R Square & 0,374 \\
Adjusted R Square & 0,325 \\
Standard Error & 399,010 \\
\hline
\end{tabular}

Sumber : SPSS, data diolah (2020) 
Hasil uji t dalam analisis regresi linier menunjukkan bahwa nilai singnifikansi t sebesar 0,000 lebih kecil dibandingkan dengan nilai $\mathrm{p}$ value $(0,05)$ sehingga waktu lingkar berpengaruh secara signifikan terhadap hasil tangkapan seperti telihat pada Tabel 2 di bawah ini. Kecepatan waktu melingkar gerombolan ikan akan berpengaruh terhadap jumlah tangkapan dikarenakan semakin lama waktu melingkar maka peluag ikan untuk lolos semakin besar.

Tabel 2. Hasil analisis regresi linier sederhana

\begin{tabular}{lccc}
\hline \multirow{2}{*}{ Model } & \multicolumn{2}{c}{ Unstandardized Coefficients } & Sig. \\
\cline { 2 - 4 } & B & Std. Error \\
\hline Constant & 2200,044 & 327,027 & 0,000 \\
Waktu lingkar & $-544,023$ & 138,471 & 0,000 \\
\hline
\end{tabular}

Sumber : SPSS, data diolah (2020)

Berdasarkan nilai koefisien tersebut, dapat dibentuk persamaan regresi sebagai berikut :

$$
y=2200-544 x
$$

Persamaan regresi tersebut dapat diartikan setiap peningkatan 1 detik waktu untuk melingkar jaring maka akan menurunkan hasil tangkapan sebesar 544 $\mathrm{kg}$. Penangkapan tidak hanya di pengaruhi oleh kecepatan lingkar dan waktu tarik, akan tetapi keahlian seorang nahkoda kapal dan anak buah kapal (ABK). Disisi lain faktor arus dan angin menjadi penentu juga. (Maulana et al., 2017) menyatakan waktu lingkar lebih berpengaruh dari waktu tarik dimana $\mathrm{R}=-0,527$ atau $27,8 \%$ sedangkan waktu tarik $\mathrm{R}=0,182$ atau $3,3 \%$.

Berdasarkan pengalaman selama kegiatan penangkapan ikan. Jumlah ikan atau gerombolan ikan (schooling) yang akan dilingkar sangat berpengaruh terhadap hasil tangkapan. Makain banyak gerombolan ikan makan akan semakin besar peluang gerombolan ikan yang akan tertangkap, begitu juga semakin kecil gerombolan ikan maka akan semakin sedikit jumlah ikan yang akan tertangkap. Disisi lain keberaadaaan ikan diperairan akan di pengaruhi apakah ikan tersebut naik ke permukaan atau tidak. Jika ikan naik kepermukaan air secara langsung memberikan pengaruh yang besar juga terhadap hasil tangkapan. Dimana jika ikan naik kepermukaan air saat melingkar memiliki peluang kecil pada ikan untuk dapat melolosan diri pada bagian bawah jaring walaupun penarikan talikolor/tali cincin berjalan lambat. Keberadaan pemangsa dalam kegiatan memlingkar akan menjadi titik balik dalam kesuksesan penangkapan. Dimana pada saat akan melingkar terdapat ikan lumba-lumba akan membuat ikan berpencar dan peluang mendapatkan hasil tangkapan yang banyak akan kecil.

\section{Pengaruh Waktu Tarik Tali Kerut Terhadap Terhadap Hasil Tangkapan}

Penarikan tali kerut dilaksanakan pada saat pelampung tanda awal dengan kapal bertemu atau sering disebut juga kedua tali pelampung bertemu. Penarikan tali kerut menggunakan alat bantu gardan. Penarikan tali kerut selesai disaat semua cincin-cincin naik ke atas kapal. Lama penarikan tali kerut berkisaran antara 9201200 detik dengan rata-rata hasil tangkapan $946 \mathrm{~kg}$. Hasil tangkapan tertinggi diperoleh pada saat penarikan tali kerut dengan waktu 980 detik dengan hasil tangkapan sebanyak $1600 \mathrm{Kg}$. Tangkapan paling sedikit terjadi pada saat penarikan tali kerut dengan waktu 990 detik.

Hasil analisis data yang telah dilakukan dengan menggunakan regresi linear sederhana mendapat nilai koefisien 
korelasi (r) sebesar 0,428 sehingga dapat diambil kesimpulan bahwa tingkat korelasi atau hubungan linear antara lama penarikan tali kerut dengan total hasil tangkapan termasuk kedalam kategori cukup kuat. Nilai koefisien determinasi $\left(\mathrm{r}^{2}\right)$ yang diperoleh sebesar 0,183 , dari nilai $\mathrm{r}^{2}$ yang diperoleh dapat disimpulkan bahwa pengaruh waktu penarikan tali kerut terhadap hasil tangkapan sebesar 0,183 atau $18,3 \%$ dan sisanya $81,7 \%$ dipengaruhi oleh variable lain. Data yang dipaparkan diatas dapat dilihat pada Tabel 3 dan 4.

Tabel 3. Hasil analisis koefisien determinasi

\begin{tabular}{lr}
\hline & Regression Statistics \\
\hline Multiple R & 0,428 \\
R Square & 0,183 \\
Adjusted R Square & 0,155 \\
Standard Error & 446,419 \\
\hline
\end{tabular}

Sumber : SPSS, data diolah (2020)

Hasil uji t dalam analisis regresi linier sederhana menunjukkan bahwa nilai singnifikansi t sebesar 0,016 lebih kecil dibandingkan dengan nilai $\mathrm{p}$ value $(0,05)$ sehingga waktu tarik berpengaruh secara signifikan terhadap total hasil tangkapan seperti telihat pada Tabel 5 di bawah ini.

Tabel 4. Hasil analisis regresi linier sederhana

\begin{tabular}{|c|c|c|c|}
\hline \multirow[t]{2}{*}{ Model } & \multicolumn{2}{|c|}{ Unstandardized Coefficients } & \multirow[t]{2}{*}{ Sig. } \\
\hline & B & Std. Error & \\
\hline Constant & 4510,657 & 1400,446 & 0,003 \\
\hline Waktu_tarik & $-3,570$ & 1,400 & 0,016 \\
\hline
\end{tabular}

Sumber: SPSS, data diolah (2020)

Berdasarkan nilai koefisien tersebut, dapat dibentuk persamaan regresi sebagai berikut :

$$
y=4510-3,57 x
$$

Persamaan regresi tersebut dapat diartikan setiap peningkatan 1 detik waktu untuk menarik jaring maka akan menurunkan hasil tangkapan sebesar 3,57 atau $4 \mathrm{~kg}$. Ketika dilakukan uji lanjut lama waktu tarik tidak terlalu berpenagruh terhadap hasil tangkapan dimana ikan akan berkumpul pada rumpon dan cahaya lampu yang sangat berguna untuk mengontrol agar ikan terpusat pada suatu bagian tertentu di perairan. (Maulana et al., 2020) waktu tarik tali kerut tidak terlalu berpengaruh terhadap hasil tangkapan. Namun waktu tarik akan sangat berpengaruk jika penangkapan dilakukan pada siang hari dan mengejar gerombolan ikan.

Proses penarikan tarik tali kerut merupakan proses yang menyebabkan jaring purse seine membentuk kantong/mangkuk sehingga gerombolan ikan masuk dalam jaring. Sehingga, waktu penarikan tali kerut yang semakin cepat akan membuat peluang ikan meloloskaan diri semakin kecil. Kecepatan tarik tali kerut akan memiliki peranan yang besar jika pada saat melingkari gerombolan ikan keberadaan ikan berada pada kolam air/ tidak naik ke permukaan air. Dimana disaat ikan tidak naik kepermukaan peluang gerombolan ikan untuk lolos akan sangat besar. Karna bagian jaring masih memiliki yang terbuka pada bagian bawah. Kecepatan penarikan tali kerut akan membuat jaring berbentuk kantong. Pada saat jaring sudah berbentuk kantong 
peluang ikan untuk meloloskan diri ketika sudah terkurung sudah tidak ada

\section{SIMPULAN}

Kesimpulan dari penelitian ini adalah tingkat korelasi antara waktu setting dengan total hasil tangkapan termasuk kedalam kategori sangat cukup erat dan tingkat korelasi antara lama penarikan tali kerut dengan total hasil tangkapan juga termasuk kedalam kategori cukup erat. Hasil uji t untuk masing-masing variable bebas menunjukkan bahwa lama setting dan lama penarikan tali kerut pada alat tangkap pukat cincin berpengaruh terhadap total hasil tangkapan.

\section{DAFTAR PUSTAKA}

Cahya, C. N., Setyohadi, D., \& Surinati, D. (2016). Pengaruh parameter oseanografi terhadap distribusi ikan. Oseana. Volume 41 No.4. hal: 1-14.

Chodrijah, U., \& Hariati, T. (2017). Musim penangkapan ikan pelagis kecil di Laut Jawa. Jurnal Penelitian Perikanan Indonesia. Volume 16 No. 3. hal: 217-233.

Demi, L. A., Waas, H. J. D., Sarianto, D., \& Haris, R. B. K. (2020). Karakteristik Oseanografi Pada Daerah Penangkapan Ikan Tuna Di Samudra Hindia Bagian Timur Indonesia. Jurnal Ilmu-Ilmu Perikanan Dan Budidaya Perairan. Volume 15 No.1. hal: 48-62.

Hermawan, O. D., asryanto, \& sardiyatmo. (2016). Hubungan lama waktu pelingkaran jaring dan penarikan tali kerut terhadap total hasil tangkapan alat tangkap purse seine di Muncar, Kabupaten Banyuwangi, Jawa Timur. Journal of Fisheries Resources Utilization Management and Technology. Volume 5 No.2. hal: 1-9.

Martasuganda, S., Sudrajat, A., Saad, S., Purnomo, J., Basuki, R., Asyik,
M., Rustam, S., Christano, D. (2004). Teknologi untuk pemberdayaan masyarakat pesisir. Seri Alat Tangkap Ikan. Jakarta: Departemen Kelautan Dan Perikanan Indonesia.

Maulana, F., Yusuf, A., Thoriq, A., \& Sugandi, W. K. (2020). Analisis Kelayakan Ekonomi Usaha Penyewaan Ammdes Pengolah Kopi Untuk Aktifitas Pengolahan Kopi Huller Dan Pulper. Jurnal Teknologi Pertanian Andalas. Volume 24 No.2. hal: 166-171.

Maulana, Sardiyatmo, S., Kurohman, F. (2017). Pengaruh Lama Waktu Setting dan Penarikan Tali Kerut (Purse Line) terhadap Hasil Tangkapan Alat Tangkap Mini Purse Seine di Pelabuhan Perikanan Nusantara Pekalongan. Journal of Fisheries Resources Utilization Management and Technology. Volume 6 No.4. hal 11-19.

Nuzapril, M., Susilo, S. B., Panjaitan, J. P. (2017). Hubungan antara konsentrasi klorofil-a dengan tingkat produktivitas primer menggunakan citra satelit landsat8. Jurnal Teknologi Perikanan Dan Kelautan. Volume 8 No.1. hal: 105-114.

Olii, P., \& Iwan, I. (2018). Produktivitas Pukat Cincin (Purse seine) Untuk Penangkapan Ikan Cakalang (Katsuwonus pelamis) Di Perairan Kabupaten Boalemo. Gorontalo Fisheries Journal. Volume 1 No.1. hal 33-42.

Pravin, P. (2002). Purse seine and its operation. Central Institute of Fisheries Technology.

Simbolon, D., Silvia, S., Wahyuningrum, P. I. (2013). Pendugaan Thermal Front dan Upwelling sebagai Indikator Daerah Potensial Penangkapan Ikan di Perairan Mentawai (The Prediction of Thermal Front and Upwelling as 
Indicator of Potential Fishing Grounds in Mentawai Water). Marine Fisheries: Journal of Marine Fisheries Technology and Management. Voleme 4 No.1. hal : 85-95.

Arikunto, Suharsimi. (2019). Prosedur Penelitian. Rineka Cipta. Jakarta

Tambun, R., Simbolon, D., Wahju, R. (2018). Zona Potensial Penangkapan Ikan Berdasarkan
Musim di Wppnri 718. Jurnal Ilmu Dan Teknologi Kelautan Tropis. Volume 10 No.3. hal: 757-768.

Yanis, M., Marwan, C., Miswar, E. (2018). Pengaruh Waktu Lingkar Alat Tangkap Pukat Cincin (Purse Seine) Terhadap Hasil Tangkapan di Perairan Sawang Ba'u, Aceh Selatan. Jurnal Ilmiah Mahasiswa Kelautan Perikanan Unsyiah. Volueme 3No.2. hal : 92-98 